\title{
Tribological Performance of a Polymer Blend of NBR Used for Stern Bearings
}

\author{
Qin Hongling $^{*}, 1,2,3$, Zhou Xincong ${ }^{1,2}$, Xu Chuntao ${ }^{1,2}$, Wang Hao ${ }^{1,2}$ and Liu Zhenglin ${ }^{1,2}$ \\ ${ }^{I}$ Reliability Engineering Institute, School of Energy and Power Engineering, Wuhan University of Technology, Wuhan \\ Hubei 430063, China \\ ${ }^{2}$ Key Laboratory of Marine Power Engineering \& Technology (Ministry of Communications) , Wuhan University of \\ Technology, Wuhan Hubei 430063, China \\ ${ }^{3}$ Hubei Key Laboratory of Hydroelectric Machinery Design \& Maintenance, China Three Gorges University, Yichang \\ 443002, China
}

\begin{abstract}
Nitrile-butadiene rubber (NBR) and another polymer with an excellent self-lubricating property are blended to develop a new kind of polymer used for water-lubricated stern bearings. The tribological performance of the new Polymer Blend of NBR (PBN), with the comparison of a rubber common used for most stern bearings, was studied using a stern bearing test rig of SSB-100. The results showed that the friction coefficients of PBN are lower than those of NBR under water-lubricated conditions. And the difference is the most evident at speeds of $0.1 \sim 2.0 \mathrm{~m} / \mathrm{s}$. So PBN will change to Plasto-Elastohydrodynamic (PEH) Lubrication at lower speed to reduce the critical speed of bearing squeal. This indicates blending rubber with other polymers is an effective means to develop low-friction stern bearing materials. Furthermore, test results revealed that reducing the rubber layer thickness and hardness will reduce the friction coefficients. So in the structure design of water-lubricated rubber bearings, selecting proper structural parameter will improve the tribological performance.
\end{abstract}

Keywords: Nitrile -butadiene rubber(NBR), polymer blend, tribological performance, stern bearing.

\section{INTRODUCTION}

Stern bearings are important components of ship propulsion system, whose performance has an important influence on sailing rapidity, security, elusive and viability for ships, especially for naval vessels. Wear, friction, and noise were considered to be the critical elements of waterlubricated stern bearing performance. Since 1840, when the first effective water-lubricated bearings were invented by John Penn [1], the need for improved water-lubricated bearing materials has been always surfacing before stern bearing designers and users.

In 2001, Othman et al. [2] studied laminated rubber bearings consisting of alternate layers of rubber and metal plates. He found that prolonging exposure to heat may affect the physical properties of rubber.

From 2002 to 2008, a number of investigations related to the tribological properties of PEEK and PEEK composites have been reported [3-8].

Also in 2002, Zhou et al. [3] determined the friction and wear properties of several metal oxides filled PTFE composites on an MM-200 test rig. The result indicated that metal oxide filled PTFE-based composites in sliding against

*Address correspondence to this author at the School of Energy and Power Engineering, Wuhan University of Technology, Y130 Post Box, Yujiatou Campus, Wuhan University of Technology, Wuhan 430063, China;

Fax/Tel: +86-717-6397559; E-mail: HHqh111120@qq.com stainless steel had smaller friction coefficients and larger wear rates under water lubrication than under dry sliding.

In 2003, Wang et al. [4] studied UP filled with MMT prepared by intercalation polymerization. The resulting materials showed much better wear resistance than the UP matrix, while the friction-reducing ability rose slightly.

In 2004, Xiao et al. [5] proposed a paper on modification of BTG plastic alloy with nanometer Zinc Oxide Whisker. Their experiment showed the effect of the content of Zinc Oxide Whisker on compound rubber hardness, tensile strength, friction coefficient, and Akron abrasion. Based on the observation of Xiao et al. [5], Peng et al. [6] selected a vulcanize system, stronger filling-in system, fence system, and intenerate increase mold system to advance the mechanical performance of BTG plastic alloy by Orthogonal experiment. Jia et al. [7, 8] investigated the tribological characteristics of carbon fiber reinforced polymer composites under distilled-water-lubricated-sliding and drysliding against stainless steel. Wear testing and SEM analysis show that all the composites hold the lowered friction coefficient and show much better wear resistance under water lubricated sliding against stainless steel than those under dry sliding.

In 2005, Litwin et al. $[9,10]$ showed their interesting in the comparison of hydrodynamic bearing with the typical main shaft bearing with a grooved bearing bushing working in a semi fluid friction conditions, of hybrid bearing with two others bearings. In the same year, Orndorff et al. [11] 
reported a new family of polymer alloy bearings which independent lab testing and field trials have verified significant wear and friction reductions are possible.

In 2008, Wu [12] gave a three-dimensional free modal and analyzed stress distribution of the bearing in numerical simulating with FEM software. He hoped the modal and harmonic analyzing results could be used directly in material design and also the improvement of structure. Hen [13] determined the mechanical properties of polyimide composites reinforced with shortcut fibers such as carbon, glass, and quartz fibers. In the same year, Meng [14] researched the friction and wear behavior of carbon nanotube reinforced polyamide 6 composites under dry sliding and water lubricated condition comparatively at different normal loads.

In 2011, Ginzburg [15] presents a retrospective review of the influence of various factors on the carrying capacity of a number of polymers and polymeric composites at boundary sliding against metals under water lubrication on the basis of their numerous publications in the field over many years.

A well-known friction phenomenon of audible nature, including chatter and squeal, can take place in stern bearings during start-up, shut-down, running with heavy load, low speed, high temperature and other special conditions. This phenomenon is mainly induced by stick/slip which is in connection with the tribological property of mating pair, such as negative slope of friction-velocity relation $[16,17]$. The purpose of this work described in this manuscript was to reveal the tribological property of the new polymer blend for stern bearing inner facing material, with comparison to a nitrile-butadiene rubber (NBR) that used for most marine ship stern bearing, especially at the speed less than $2.0 \mathrm{~m} / \mathrm{s}$. The new polymer blend is blended from NBR and a high molecular weight material with good self-lubrication and abrasion resistant performance. Primary criteria of the Polymer Blend from NBR (PBN) are the reduction of breakaway and low shaft speed friction, and the bearing noise, which will improve the security and viability of naval vessels.

\section{EXPERIMENTAL DETAILS}

\subsection{Specimen Preparation and Test Procedure}

In this study, a part of a stern bearing stave was taken as test blocks shown in Fig. (1). The size of test block with flat top is $70 \mathrm{~mm}$ in length, $32 \mathrm{~mm}$ in width, and $23.5 \mathrm{~mm}$ in thickness with flat top. And the facing layer was made from NBR and PBN with different thickness and hardness separately. Some parameters of test blocks are tabulated in Table 1.

The friction tests were performed at room temperature under pressures of $0.15,0.2,0.3,0.4,0.5,0.6 \mathrm{MPa}$ pressures and shaft velocity of $0.1,0.2,0.5,1.0,1.5,2.0,2.5,3.0,3.5,4.0$ $\mathrm{m} / \mathrm{s}(13,26,64,128,192,257,321,385,449,513 \mathrm{r} / \mathrm{min})$ in tap water lubricated condition. These tests also run at different facing layer thickness $(4 \mathrm{~mm}, 8 \mathrm{~mm}, 12 \mathrm{~mm})$ and hardness (70 A and $82 \mathrm{~A}$ ). Test procedure was as follows: at an applied pressure, according to velocity grade requirement $(0.1,0.2,0.5,1.0,1.5,2.0,2.5,3.0,3.5,4.0 \mathrm{~m} / \mathrm{s})$, changing the journal velocity every 15 minutes to increase the journal velocity from $0.1 \mathrm{~m} / \mathrm{s}$ to $4.0 \mathrm{~m} / \mathrm{s}$ gradually, and then to decrease from $4.0 \mathrm{~m} / \mathrm{s}$ to $0.1 \mathrm{~m} / \mathrm{s}$ in reverse order. In the process, record friction torque and coefficient in each velocity grade. And so forth 5 times, take the average value of 10 records as the results. Each test was repeated three times and the close results were considered and their average values were obtained.

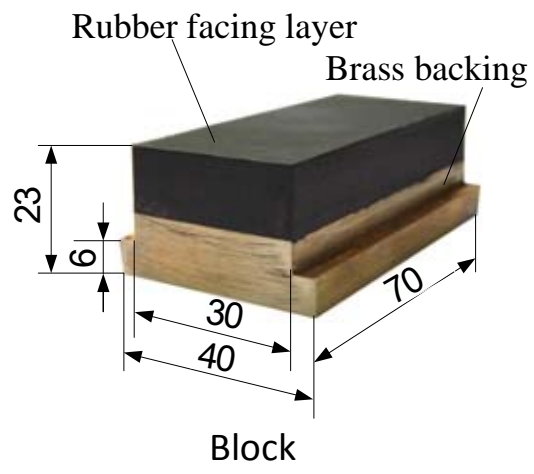

Fig. (1). Test Block.

Table 1. Details of Facing Layer of Test Blocks

\begin{tabular}{|c|c|c|c|c|c|c|c|c|c|c|c|c|}
\hline Material & \multicolumn{5}{|c|}{ NBR } & \multicolumn{6}{c|}{ PBN } \\
\hline $\begin{array}{c}\text { Shore } \\
\text { hardness } \\
\text { (A) }\end{array}$ & \multicolumn{2}{|c|}{70} & \multicolumn{2}{|c|}{82} & \multicolumn{3}{|c|}{70} & \multicolumn{3}{c|}{80} \\
\hline $\begin{array}{c}\text { Thickness } \\
\text { (mm) }\end{array}$ & 4 & 8 & 12 & 4 & 8 & 12 & 4 & 8 & 12 & 4 & 8 & 12 \\
\hline
\end{tabular}

\subsection{Test Rig}

Test was carried out on the SSB- 100 stern bearing test rig developed by Wuhan University of Technology in Fig. (2). As shown in this figure, the rig consists of a variable

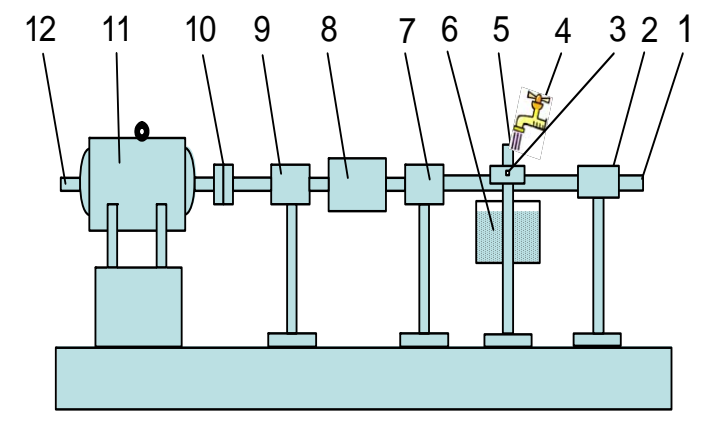

$\begin{array}{llll}\text { 1. Main Shaft } & \text { 2. Ball Bearing } & \text { 3. B\&K Pulse } & \text { 4. Water Lubrication System } \quad \text { 5. Tank Lever Loading Device } \quad \text { 6. Water }\end{array}$ Pool 7. Hydrostatic Spherical Bearings 8. Friction Torque Measuring Instrument 9. Ball Bearing 10. Coupling $\begin{array}{ll}\text { 11. Variable Frequency Motor } & \text { 12. Speed Sensor }\end{array}$

Fig. (2). Test rig.

speed motor which can provide two-way motion to the main shaft. The main shaft is made from 45 steel, with the journal set with ZQSn10-2 bushing with a diameter of $149 \mathrm{~mm}$, which is the mating pair of facing layer of test blocks. Water lubrication system can adjust the tap water temperature and flow according to test requirements. Lever loading system is depicted in Fig. (3). By the ratio of lever arm, we can attain the radial load $Q$ acting on the test block from Eq. (1).

$$
Q=0.111+0.02 P Q_{1}
$$


where $Q$ is radial load acting on the test block $(\mathrm{kN}), Q_{1}$ is load weight $(\mathrm{N})$. Measurement system consists of three subsystems, plotted in Fig. (4). The friction torque measuring instrument is a very sensitive differential gear torque measuring system and mounted on the main shaft to measure friction torque $M$. The speed sensor is to measure real-time speed. And the two B\&K pulses were mounted on the lever to measure horizontal and vertical vibration signals. All of the original signals are transmitted to a PC for analysis and processing by 3560 Multi-channel Analyzer.

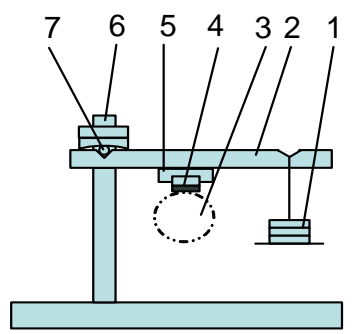

1.Loading weight 2.Loading Arm 3.Main Shaft 4.Test Block 5.Fixture 6.Backstop 7.Pin

Fig. (3). Lever loading system.

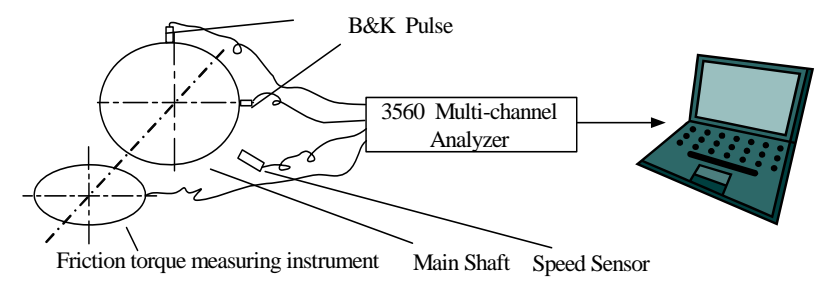

Fig. (4). Measurement system.

In a stave bearing, each stave functions as an individual bearing surface. The applied stave acts vertically in a normal full bearing. The bottom stave carries most of the load, about $28.787 \%$ of the radial load for our test conditions [18]. To compare with full bearings, the projected pressure on the test sample was calculated as if the sample was a segment of the heaviest loaded stave in a full bearing operating at the projected pressure (bearing radial load divided by the product of the bearing bore diameter and the axial length).

So friction coefficient $f$ was calculated as follows:

$$
P=\frac{Q}{\alpha \times d \times l}
$$

$F=\frac{M}{r}=\frac{2 M}{d}$

$f=\frac{F}{Q}=\frac{2 M}{\alpha \times d^{2} \times l \times P}=\frac{M}{223.685 P}$

in which $M$ denotes friction torque $(\mathrm{N}), F$ friction force $(\mathrm{N})$, $P$ the equivalent projected pressure (MPa), $d$ journal diameter of main shaft $(\mathrm{mm}), l$ journal length of main shaft ( $\mathrm{mm}$ ), and $\alpha=0.28787$ [18].

\section{RESULTS AND DISCUSSIONS}

\subsection{The Relationship Between Friction Coefficient and Velocity}

The facing layer of the test blocks used in this trial was $12 \mathrm{~mm}$ thick and 82A hard. Fig. (5) presents the variation of friction coefficient for PBN and NBR with the change of velocity in applied pressure under water lubrication conditions. As shown in this figure, whether PBN or NBR, the friction coefficient decreased firstly, and then stabilized, and finally increased slightly with velocity increasing. At low speed of $0.1 \sim 2.0 \mathrm{~m} / \mathrm{s}$, there was a direct contact between the journal and the bearing which could be either dry (with a high friction coefficient), or partially lubricated (with a lower friction coefficient). Therefore, the friction coefficient was larger. However, with the speed increasing, the rotating journal drew more water into contact area, which was conducive to elimination of dry contact region, and to formation of lubricant film, and to increase of the fluid pressure. Thus the friction coefficient decreased impressively. When the speed was between $2.0 \mathrm{~m} / \mathrm{s}$ and $3.5 \mathrm{~m} / \mathrm{s}$, the rubber deflected initially elastically and then plastically due to creep, forming a lubricant-trapping pocket. This effect was called Plasto-Elastohydrodynamic (PEH) Lubrication [1, 19]. Due to PEH lubrication, the friction coefficient gradually decreased and then stabilized. When the speed was more than $3.5 \mathrm{~m} / \mathrm{s}$, the increasing velocity led the journal and bearing surface to contacting each other more frequently. The surface temperature rose and some of the lubricant film broke down. The friction coefficient increased slightly.

Furthermore, it's clear that friction coefficient of PBN was less than that of NBR in most cases. At the speed of 0.1 $\sim 2.0 \mathrm{~m} / \mathrm{s}$, this phenomenon was the most prominent, especially under the pressure of $0.3,0.4,0.5,0.6 \mathrm{MPa}$ (Fig. (5) $\mathrm{c} \sim \mathrm{f}$ ). It implied that the ingredient with an excellent selflubricating property in PBN played a very good improvement role for the tribological properties of NBR.

At start-up, the smaller the friction coefficient, the lower the critical speed of bearing noise (is defined as the highest speed when vibration noise occurs in the stern bearing during the decrease of journal speed.) occurrence caused by stick - slip effect. It could thus be concluded that, PBN showed a clear superiority at the low speed, under medium load.

\subsection{The Relationship Between Friction Coefficient and Pressure}

Fig. (6) presents the variation of friction coefficient of PBN with hardness of $82 \mathrm{~A}$ and $70 \mathrm{~A}$ with the change of projected pressure under water lubrication conditions. As shown in Fig. (6), the friction coefficient decreased impressively as the projected pressure increases when the journal velocity was between $0.1 \sim 2.0 \mathrm{~m} / \mathrm{s}$, but changed slightly when the journal velocity is more than $2.0 \mathrm{~m} / \mathrm{s}$. As mentioned above, at lower speed of $0.1 \sim 2.0 \mathrm{~m} / \mathrm{s}$, there was a direct contact between the journal and the bearing which could be either dry, or partially lubricated. The friction pair was in the mixed film regime. With the pressure increasing, the real contact area increased, then the actual contact stresses between the asperities reduced (the real contact area could be calculated by measuring the wear scar on the flat test block at the end of the test after the load was removed), so the friction coefficient decreased. When the journal velocity was greater than $2.0 \mathrm{~m} / \mathrm{s}$, the friction pair was in the state of PEH lubrication regime, so the pressure had little effect on the friction coefficient. 


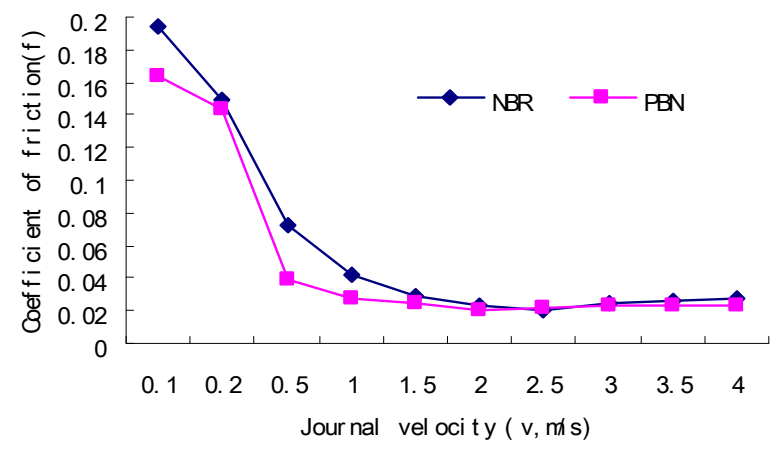

(a) $0.15 \mathrm{MPa}$

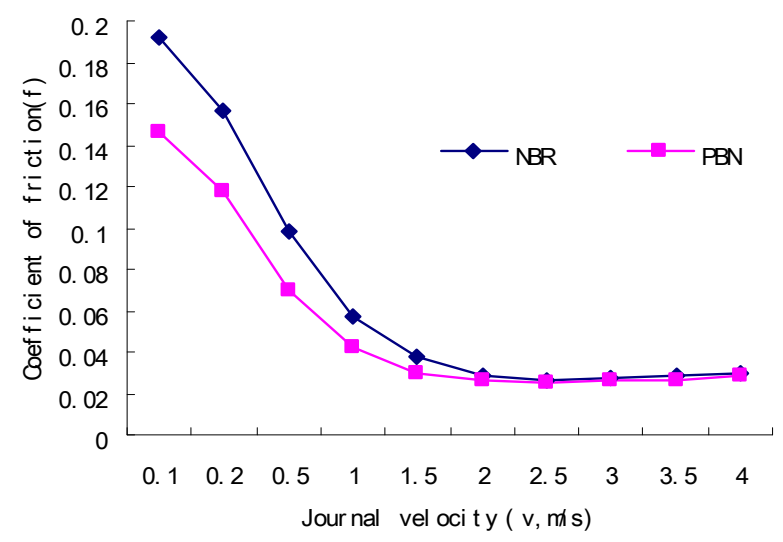

(c) $0.3 \mathrm{MPa}$

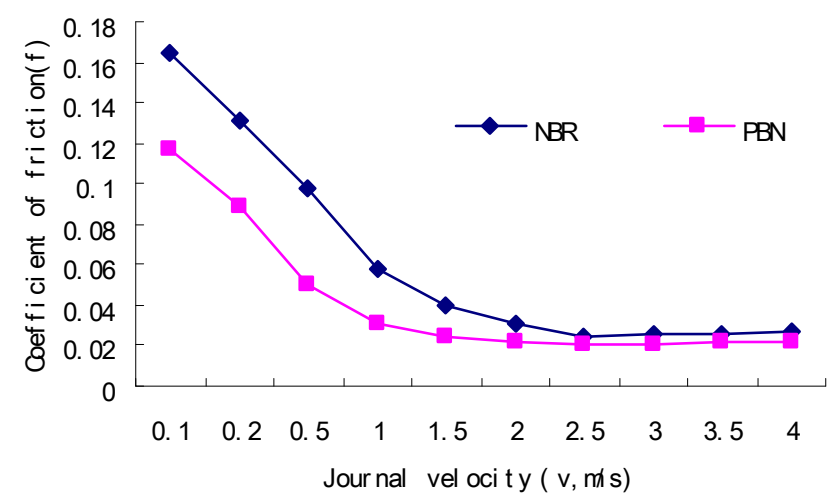

(e) $0.5 \mathrm{MPa}$

Fig. (5). Friction coefficient comparison, PBN $v s$ NBR.

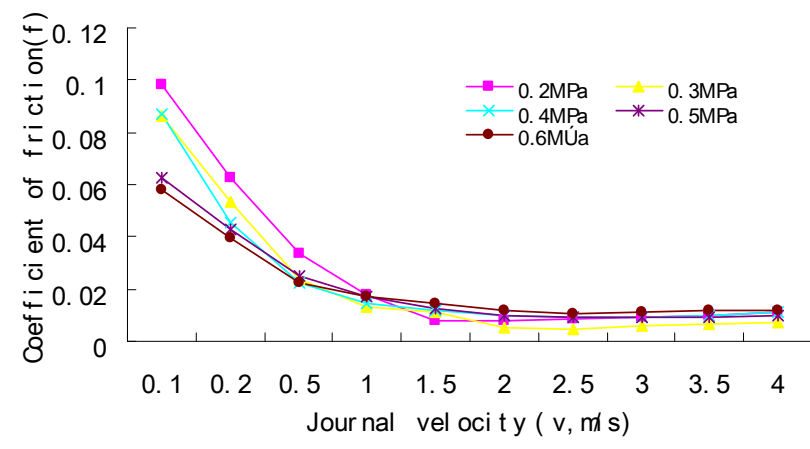

(a) PBN, 70A, $12 \mathrm{~mm}$

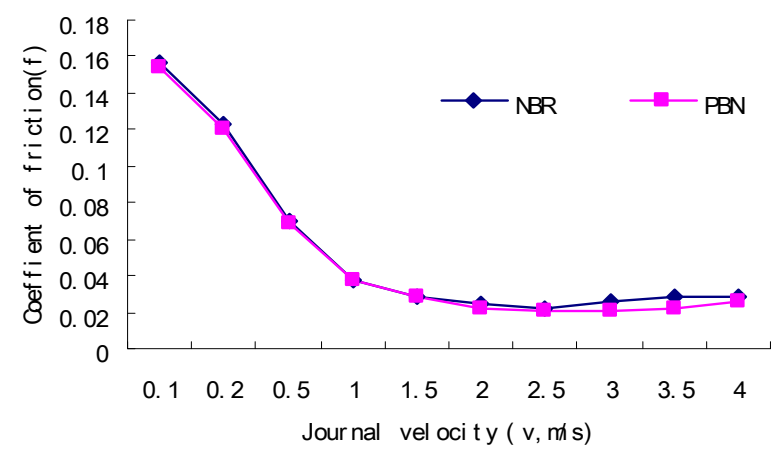

(b) $0.2 \mathrm{MPa}$

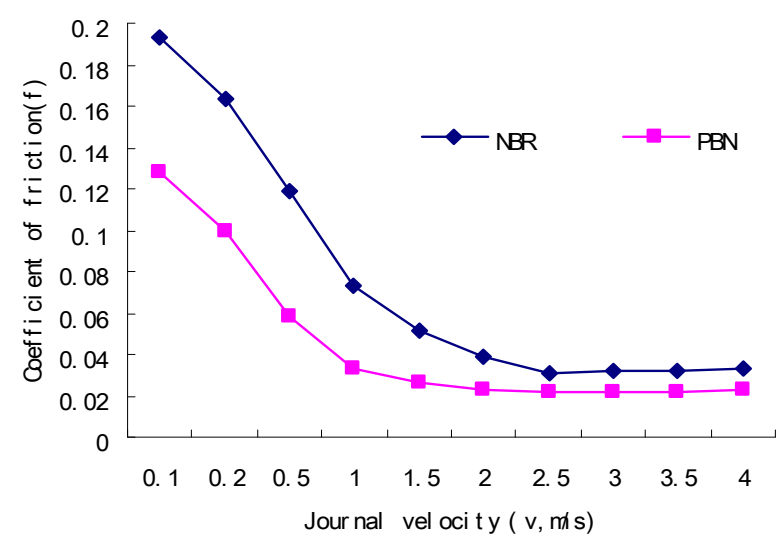

(d) $0.4 \mathrm{MP}$

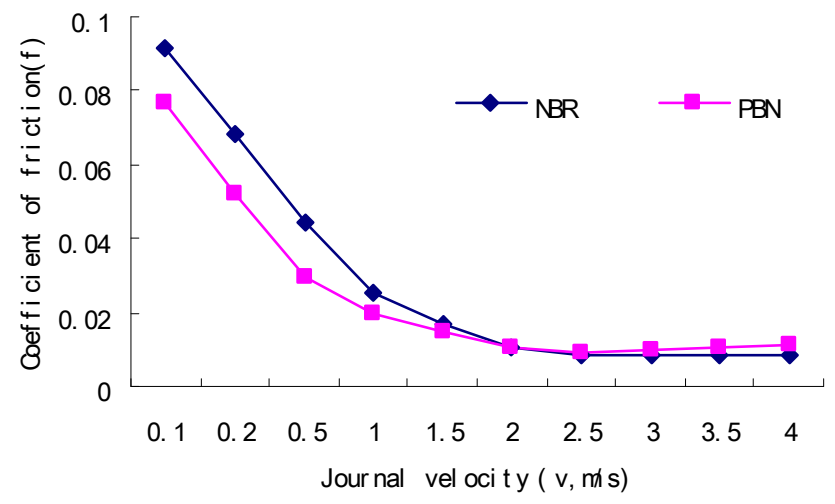

(f) $0.6 \mathrm{MPa}$

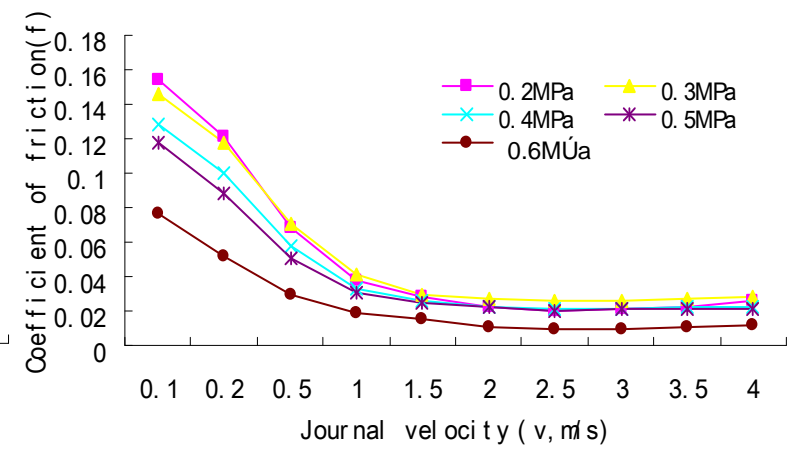

(b) PBN, 82A, $12 \mathrm{~mm}$

Fig. (6). Friction coefficient vs projected pressure. 


\subsection{The Relationship Between Friction Coefficient and Rubber Layer Thickness}

Fig. (7) presents the variation of friction coefficient for PBN and NBR with different facing layer thickness, applied pressures, test speeds under tap water lubricated conditions. It's clear from these figures that a significant increase in friction coefficient was observed for the increase of facing layer thickness. As is known that PBN and NBR are high elastic and deformation under load is easy. Reducing the thickness could reduce the sinkage of the journal into the facing layer. PEH lubrication was a pumping type action, with the rotating journal drawing the lubricating fluid into the gradually decreasing approach distance and increasing the fluid pressure as a direct result. The deeper the journal sank, the smaller the wedge-shaped space was, the less the fluid exited at each of the bearing ends and the lower the pressure of water film was. This observation was consistent with the ROY's [1].

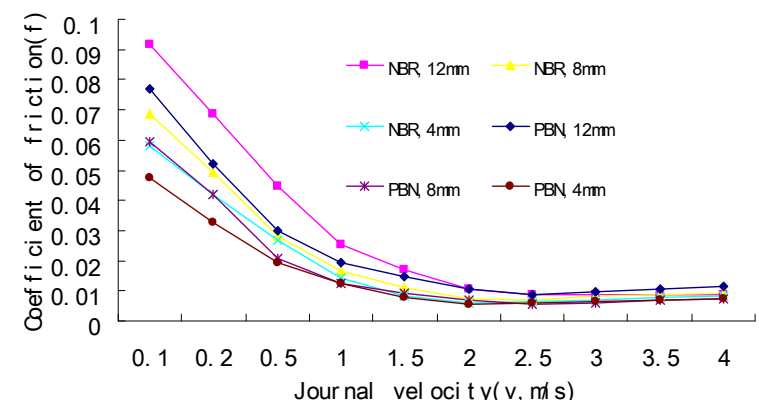

(a) $0.15 \mathrm{MPa}$

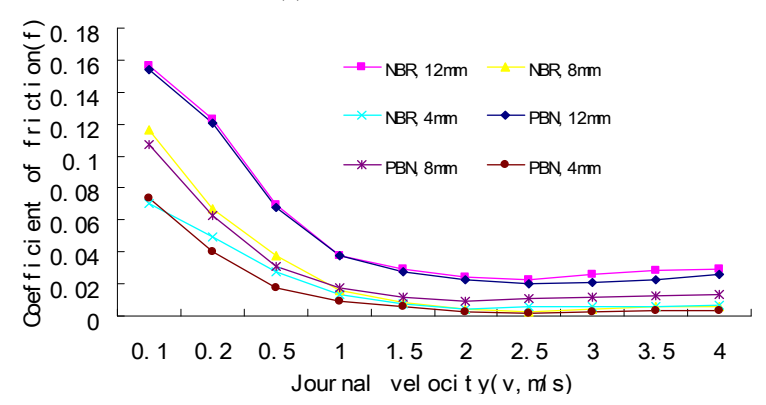

(b) $0.3 \mathrm{MPa}$

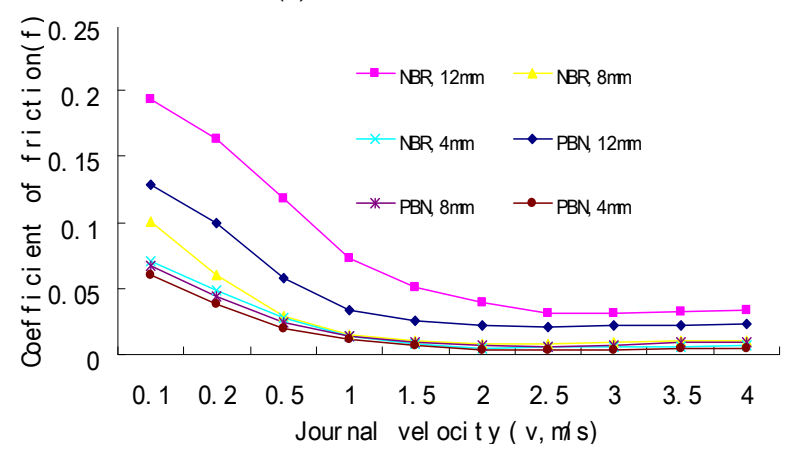

(c) $0.5 \mathrm{MPa}$

Fig. (7). Friction coefficient $v s$ thickness.

A large disparity of friction coefficient was seen between PBN and NBR. In addition, the thicker the rubber layer, the larger the disparity at the speed ranges of $0.1 \sim 2.0 \mathrm{~m} / \mathrm{s}$. PBN showed a clear superiority at the lower speed too.

\subsection{The Relationship Between Friction Coefficient and Rubber Layer Hardness}

Fig. (8) presents the variation of friction coefficient for PBN and NBR with different facing layer hardness, applied pressures, and test speeds under tap water lubricated conditions. These figures showed that the friction coefficient was influenced by the change of facing layer hardness for both PBN and NBR. The harder the rubber layer, the larger the friction coefficient was. This phenomenon was more evident at the pressure of $0.2,0.4 \mathrm{MPa}$ than $0.6 \mathrm{MPa}$. These can be explained by two factors. First, the lower hardness facing layer has a greater deformation than harder rubber layer under applied pressure, which would reduce the actual contact stress between the asperities. Second, the greater the deformation of rubber, the more significant the PEH

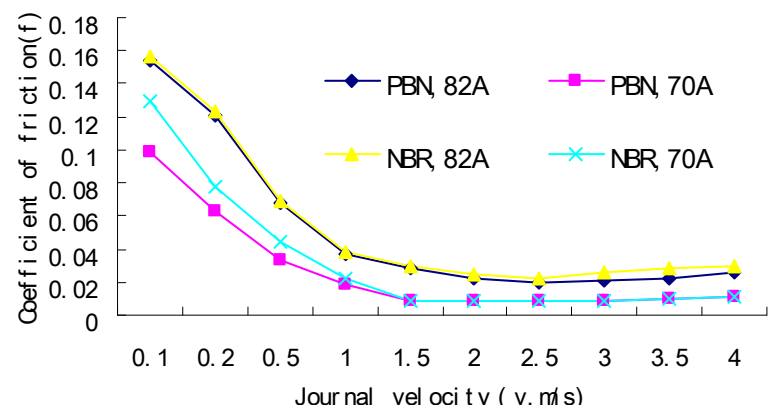

(a) $0.2 \mathrm{MPa}$

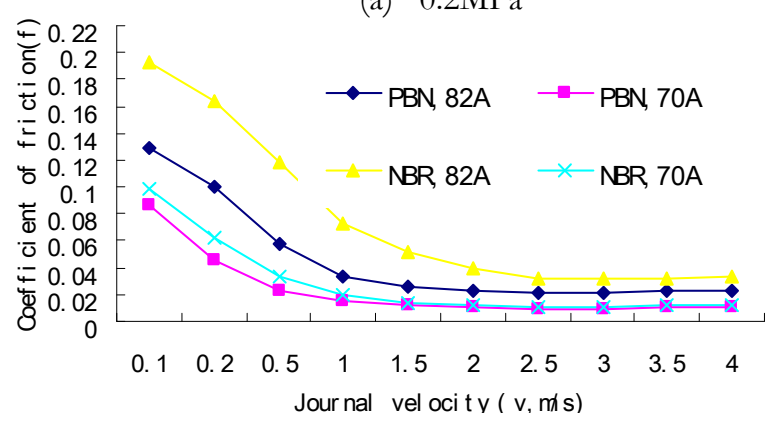

(b) $0.4 \mathrm{MPa}$

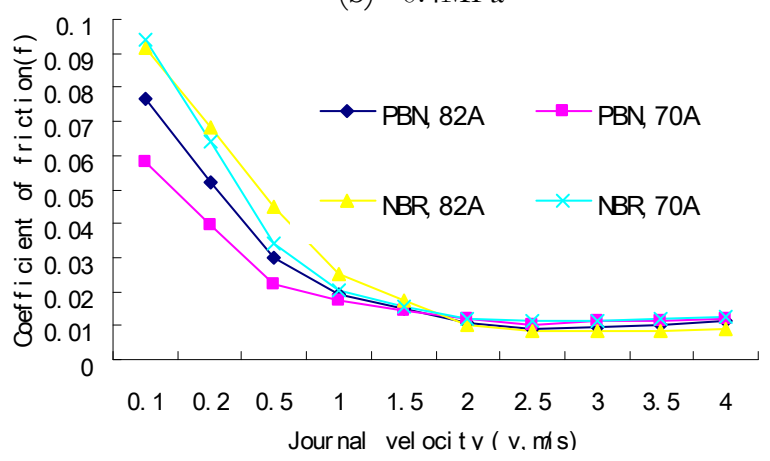

(c) $0.6 \mathrm{MPa}$

Fig. (8). Friction coefficient $v s$ hardness. 
Fig. (9). Time curve and frequency spectrum of test block vibration during bearing squeal.

lubrication effect was. These two reduced the friction coefficient of the lower hardness rubber layer. Under the pressure of $0.6 \mathrm{MPa}$, the rubber layer deformation was serious, and almost reached the limit of elastic deformation for both $82 \mathrm{~A}$ and $70 \mathrm{~A}$ test blocks. The two factors acted the same. Thus the difference between the two materials began to become smaller.

Moreover, it could also conclude that PBN shows a clear superiority at the low speed. It's indicates that the negative slope of friction-velocity relation is less steep than that of NBR. Stick-slip will partly eliminated or occur at a relative lower critical speed.

\section{BEARING SQUEAL TEST}

Bearing squeal sometimes originates in water-lubricated bearings in marine propeller shaft applications. It's believed that the noise is induced by stick-slip behavior of contact zone. The critical speed of bearing squeal is defined as the highest speed when vibration noise occurs in the stern bearing during the decrease of journal speed. The lower the critical speed, the shorter the time is needed to overgo the noise radiation area for naval vessels, and the more secure and elusive the naval vessels are.

Fig. (9) presents the time curve and frequency spectrum of test block vibration during bearing squeal of test block with $82 \mathrm{~A}$ hardness and $12 \mathrm{~mm}$ thickness under tap water lubrication. The vibration is more serious for test blocks with $70 \mathrm{~A}$ hardness and $12 \mathrm{~mm}$ thickness at the same test condition. This probably indicates that the low-hardness facing layer is inclined to generate noise easily. Record of the critical speed under pressure of $0.2,0.4,0.6 \mathrm{MPa}$ listed in Table 2.

Table 2. Critical Speed of Test Blocks with 82A Hardness and $12 \mathrm{~mm}$ Thickness

\begin{tabular}{|c|c|c|c|c|c|c|}
\hline \multirow{2}{*}{ Material/Pressure (MPa) } & \multicolumn{3}{|c|}{ NBR } & \multicolumn{3}{c|}{ PBN } \\
\cline { 2 - 8 } & 0.2 & 0.4 & 0.6 & 0.2 & 0.4 & 0.6 \\
\hline Critical Speed (m/s) & 0.27 & 0.29 & 0.30 & 0.18 & 0.19 & 0.21 \\
\hline
\end{tabular}

These figures show that, in the same condition, PBN has a lower critical speed than NBR, which confirms the deduction of section 3. It's indicates that blending rubber with other polymers is an effective approach to develop lownoise stern bearing materials.

\section{CONCLUSIONS AND RECOMMENDATIONS}

a. The friction coefficients of PBN are lower than those of NBR under tap water lubricated conditions. The difference is the most obvious at the speed of $0.1 \sim$ $2.0 \mathrm{~m} / \mathrm{s}$. It's indicates that the negative slope of friction-velocity relation is less steep than that of NBR. Stick-slip will partly eliminated or occur at a relative lower critical speed. This indicates that PBN is the very suitable for submarine vessels.

b. Reducing the rubber layer thickness will reduce the friction coefficients. However, the thickness can't be reduced infinitely; because it will shorten bearing 
service life for thin facing layers and will cause them to wear out quickly.

c. PBN has lower critical speed of bearing noise than NBR under same test conditions. Decreasing the rubber layer hardness of PBN will decrease the friction coefficients, but will increase the critical speed of bearing noise. More details are needed to fully test full stern bearings.

d. Blending rubber with other polymers is an effective methodology to develop low-noise stern bearing materials.

\section{CONFLICT OF INTEREST}

The authors confirm that this article content has no conflict of interest.

\section{ACKNOWLEDGEMENTS}

This research was supported by the National Natural Science Foundation of China under Grant no. 50979084 and 51079119 and the project of Key Natural Science Foundation of Hubei under Grant no. 2008CDA027. The authors gratefully acknowledge the support of Professor Tang Yu-min and Lecture Tian Hong-liang for their help.

\section{REFERENCES}

[1] R.L. Orndorff Jr., "Water-lubricated rubber bearings, history and new developments," Naval Engineers Journal, vol. 10, pp. 39-52, 1985.

[2] A. B. Othman, "Property profile of a laminated rubber bearing", Polymer Testing, vol. 20, pp. 159-166, 2001.

[3] H.-D. Zhou, J. Jia, J. Chen and F. Yan "Tribological behavior of metal oxides filled polytetrafluoroethylene composites under water lubrication", Mocaxue Xuebao/Tribology, vol. 22, pp. 449-453, 2002.

[4] L.-X. Wang, J. -F. Li, H.-B. Zhang and L. Ren "Friction and wear behavior of unsaturated polyester/montmorillonite intercalated nanocomposites", Tribology, vol. 23, pp. 197-200, 2003.

[5] K. Xiao, J. Wang, Y. Zhang and H. Haomi "Modification on water lubricated bearings material with nanometer zinc oxide whisker", Lubrication Engineering, pp. 38-39, 2004.

[6] J. Peng, J. Wang and M. Yang "Research on modifying mechanic performance of water lubricated plastic alloy bearings material", Lubrication Engineering, pp. 80-82, 2004.
[7] J.-H. Jia, J.-M. Chen, H.-D. Zhou and L. Chen, "Wear and transfer characteristics of carbon fiber reinforced polymer composites under water lubrication," Transactions of Nonferrous Metals Society of China (English Edition), vol. 14, pp. 332-340, 2004.

[8] J. Jia, C. Jianmin, Z. Huidi, H. Litian and C. Lei "Comparative investigation on the wear and transfer behaviors of carbon fiber reinforced polymer composites under dry sliding and water lubrication", Composites Science and Technology, vol. 65, pp. 1139-1147, 2005.

[9] W. Litwin, "Water lubricated polymer hydrodynamic bearing with full and grooved bearing bushing", In: 2005 ASME International Mechanical Engineering Congress and Exposition, November 5, 2005 - November 11, 2005, Orlando, FL, United states, 2005, pp. 49-57.

[10] W. Litwin, "Water lubricated hybrid propeller shaft with polymer bearing bush," In: 2005 World Tribology Congress III, September 12, 2005 - September 16, 2005, Washington, D.C., United states, 2005, pp. 13-14.

[11] R. Orndorff Jr, L. Foster Jr, and R. Sheppert, "From lab to field: New high performance water lubricated," In: 2005 World Tribology Congress III, September 12, 2005 - September 16, 2005, Washington, D.C., United states, 2005, pp. 55-56.

[12] X. Wu, W. Jiaxu, X. Ke and Z. Juanjuan "Numerical simulation study on water-lubricated rubber bearing", Journal of Advanced Manufacturing Systems, vol. 7, pp. 111-114, 2008.

[13] J. Chen, J. Junhong, Z. Huidi, C. Jianmin, Y. Shiyong and F. Lin "Tribological behavior of short-fiber-reinforced polyimide composites under dry-sliding and water-lubricated conditions", Journal of Applied Polymer Science, vol. 107, pp. 788-796, 2008.

[14] H. Meng, G.X. Sui, G.Y. Xie and R. Yang, "Friction and wear behavior of carbon nanotubes reinforced polyamide 6 composites under dry sliding and water lubricated condition", Composites Science and Technology, vol. 69, pp. 606-611, 2009.

[15] B. M. Ginzburg, D. G. Tochil'nikov, P. A. Shiyan, and A. O Pozdnyakov, "Carrying capacity of polymers and polymeric composites in water-lubricated friction against metals," Journal of Friction and Wear, vol. 32, pp. 150-163, 2011.

[16] R.A. Ibrahim . Friction-induced vibration, chatter, squeal, and chaos: Part I - Mechanics of friction[C]. Winter Annual Meeting of the American Society of Mechanical Engineers, vol. 49, pp. 107121, 1992.

[17] M. A. Chowdhury, H. Maksud, "The effect of relative humidity and roughness on the friction coefficient under horizontal vibration", The Open Mechanical Engineering Journal, vol. 2, 128$135,2008$.

[18] R. L. Daugherty and N. T. Sides, "Frictional characteristics of water-lubricated compliant-surface stave bearing," ASLE Transactions, vol. 24, pp. 293-301, 1981.

[19] R.L. Orndorff Jr, "New UHMWPE/rubber bearing alloy," Journal of Tribology, vol. 122, pp. 367-373, 2000. 